\title{
I Congreso Iberoamericano de Docentes: una experiencia singular
}

Joaquín Asenjo Pérez y Óscar Macías Álvarez
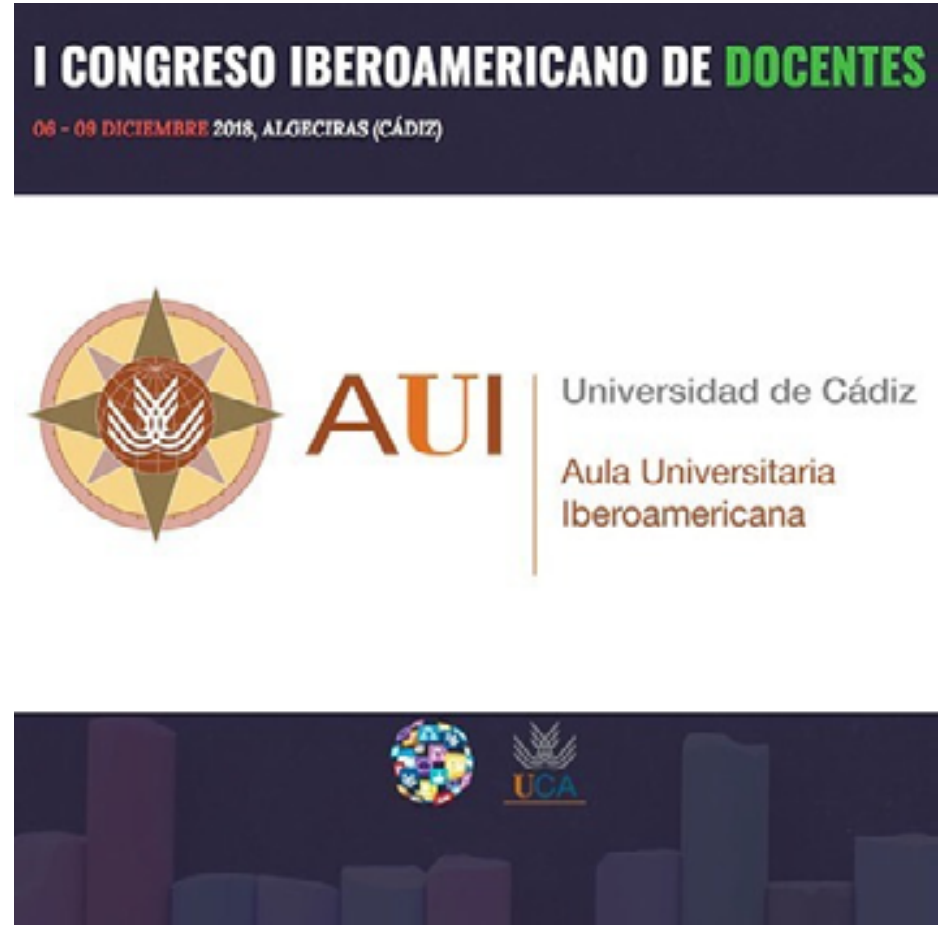

El pasado 8 de diciembre se clausuraba en el Campus Algeciras de la Universidad de Cádiz el I Congreso Iberoamericano de Docentes. Dicho de esa manera pareciera que todo quedaba pendiente para el Il cuando en realidad lo que ocurría no era más que un acto más de un Congreso que no se detiene.

Cuando en agosto de 2017 los miembros de la Red Iberoamericana de Docentes, una red con 38.500 miembros, acordaban tener en 2018 un Congreso con dos modalidades, presencial y virtual, no imaginábamos lo que venía por delante.

A las pocas semanas nos llegaban propuestas de distintos lugares de lberoamérica para ser sede de la parte presencial. Una de ellas era de Ana Villaescusa, Presidenta de la Asociación Diverciencia de Algeciras. Para nosotros, una asociación con sede en Jerez de la Frontera, era una propuesta que nos permitía dar los primeros pasos en nuestro propio entorno. En pocas semanas tanto la Universidad de Cádiz como el Ayuntamiento de Algeciras y el CEP de AlgecirasLa Línea se unían a la iniciativa y juntos empezábamos el camino al que de inmediato se unieron tanto la Fundación Campus Tecnológico como otras instituciones del Campo de Gibraltar.

$1 \quad$ Asociación Formación IB 
En enero de 2018 ya estaba convocado y se empezaron a recibir las primeras inscripciones. Habíamos logrado la colaboración de muchos académicos para configurar el Comité Científico y empezó el trabajo de organización.

Nuestra Asociación y nuestra Red se movilizó y a finales de julio habíamos recibido 1.206 propuestas de experiencias y comunicaciones para ambas modalidades. Eso ya era un primer signo de los que vendría después: habíamos logrado el interés en comunicar por parte de muchos docentes.

Siempre hemos pensado que una de las mayores necesidades que tienen los docentes de todos los niveles y modalidades es la de tener espacios en los que narrar sus innovaciones [tecnológicas o no] y el Congreso había sido capaz de mandar el mensaje del enorme que era para que la docencia tomara la palabra.

La otra necesidad que consideramos necesaria es la de colaborar. Un docente, por innovador y trabajador que sea, no puede alcanzar metas significativas trabajando en solitario. Fomentar la creación de equipos colaborativos era nuestro segundo lema. Seguramente era el reto más complicado de lograr.

Pero Iberoamérica es una región que tiene una gran fortaleza que es el sencillo entendimiento entre dos lenguas que son mantienen unas relaciones muy cordiales. Junto a ello tenemos una historia y unas raíces culturales muy semejantes.

Así llegamos al 26 de noviembre en que arrancaba el Congreso virtual que contaba con cerca de 250 comunicaciones orales y unos 70 póster y nos encontramos con la enorme alegría de ver las interacciones que se producían. Es cierto que el contacto directo es mucho más potente, pero se había logrado un ambiente que respondía a nuestro objetivo: ganas de conocer lo que hacen otros y de empezar a colaborar.

Unos días más tarde, el 6 de diciembre, empezaba la modalidad presencial. Algeciras era un destino complicado para un latinoamericano al carecer de aeropuerto. Pese a todo de los 580 participantes algo más de la mitad de ellos venían de otros países: 17 latinoamericanos, Portugal, Italia, Bélgica, Reino Unido y Estados Unidos completaban el origen de estos.

Durante el congreso teníamos 4 sedes diferentes que acogían las sesiones de comunicaciones libres, las de póster, las conferencias, las mesas redondas y, muy valorados, los talleres. El ofrecer esos talleres ha sido un gran acierto. Habíamos preparado unas preinscripciones dado que por su modalidad teníamos que ajustarnos a las limitaciones de espacio y materiales. Tratamos además de que todo interesado pudiera asistir al menos a uno y seguimos criterios equilibrados para propiciar una participación heterogénea en lo que a países se refiere. Nos comentaba Mariano Martín Gordillo que en su taller tenía 20 personas de 9 países diferentes. Esa ha sido una de las riquezas del Congreso.

Lo que para nosotros era claro era que el Congreso estaba siendo un espacio de inicio de colaboraciones, de tejer nodos articulados y de crear nuevas amistades. En muchos casos correspondía a una desvirtualización de unas largas relaciones virtuales en redes sociales.

Decíamos al inicio que el 8 de diciembre se clausuraba el Congreso. En realidad, el 10 de diciembre se relanzaba el Congreso virtual con la incorporación más decidida los participantes presenciales en el espacio. 
Nuestros siguientes pasos están siendo el ir compartiendo las grabaciones de las conferencias para que pueda ser seguida tanto por los participantes virtuales como por los presenciales que no tuvieron oportunidad de escucharlas en directo por tener otro tema en ese momento que le interesaba más o sencillamente por tener que intervenir en otro espacio paralelo.

La selección de las conferencistas y de las conferencias estamos seguros de que va a generar un nuevo impulso para crear debates y fomentar relaciones educativas.

Otra acción que estamos propiciando es que los ponentes presenciales presenten en vídeos breves sus comunicaciones para que sean seguidas por los virtuales y por los presenciales que no estuvieron en el momento de su exposición.

Todo ello nos está cerrando un Congreso muy singular. Con el rigor académico que garantizaba nuestro Comité compatible con la cordialidad en las relaciones que se van creando.

Hace pocos días recibíamos con gran satisfacción que en el Congreso Educa que selecciona a los docentes más apreciados por sus alumnos de toda España dos de ellos, Alfredo Corell y Pedro Martínez, estaban entre los 6 elegidos. Conviene señalar que Alfredo lo era en un tema del que suelen estar alejados los Congresos: la educación universitaria. Innovar y ser creativo al impartir la docencia en la universidad no suele ser habitual. Hay pocos ejemplos, entre otras razones porque los docentes universitarios vuelcan sus esfuerzos de publicación en su labora investigadora. La labor docente, quizás la esencial, suele ser poco difundida y conocida. También que el otro elegido fuera docentes de matemática y que su propuesta esencial sea la de hacer emocionante el aprendizaje de su asignatura también es significativo. La matemática es un punto clave de la educación por ser una disciplina que causa muchas fobias entre estudiantes y sus familias. En ese sentido tiene para nosotros un especial significado que tres agrupaciones de profesores de matemáticas nos apoyaran: la Federación Española de Sociedades de Educación Matemática (FESPM], la Federación Iberoamericana de Sociedades de Educación Matemática [FISEM] y finalmente la Sociedad Andaluza de Educación Matemática SAEM-Thales.

En esos premios también se destacó a una profesora gallega, Vita Martínez que, junto a Andrea Giráldez, tuvo la mayor cantidad de peticiones para su Taller. Los títulos de ambos talleres: Pedagogías tangenciales al aula-vida: habilidades para sentir el de Vita y Cambiar las conversaciones para cambiar la educación el de Andrea, muestran el interés que los temas vinculados a las emociones tienen los educadores.

En el ámbito de los actos relativos al Día de Pl celebrados en Granada el 14 de marzo se reconocía como mejor divulgador de matemáticas de España al profesor de la Universidad de Granada Álvaro Martínez Sevilla por su trabajo de Paseos Matemáticos. Algeciras pudo ser matemáticamente recorrida durante el Congreso de su mano maestra.

Y el pasado 15 de marzo en que muchos estudiantes salieron a la calle para responder al llamamiento que desde Suecia hacía Greta Thunberg tuvimos a muchos de nuestros participantes apoyando a sus estudiantes en muchos lugares de España, Portugal y América Latina. Una de las primeras actividades con el rótulo Friday forFuture lo lideraba Miriam Leiros, también participante en Algeciras,en el CEIP Antonio Palacios de O Porriño.

Una acción colaborativa que se llevó adelante en el marco del Congreso fue el lanzamiento de un Concurso de Fotografía Móvil para crear un Calendario Ambiental por estudiantes. Muchos 
docentes de Latinoamérica trabajaron durante meses promoviendo la participación y trabajando como Jurados liderados por José Heber de León Monzón de la Red Telaraña de Ciencias de Chiapas (México]. Hemos tenido la suerte de que la Alcaldía de Sogamoso [Colombia] decidiese que ese día 15 de marzo hacer un acto oficial de reconociendo a los 6 estudiantes de esa ciudad que obtuvieron distinción en el Concurso que recibió más de 1.200 imágenes de 18 países. Esa fue la manera en que estudiantes de primaria o secundaria estuvieron presentes con su trabajo en el Congreso.

\section{LOS RETOS DEL FUTURO}

Para nuestra Asociación este Congreso era el primer gran reto al que nos enfrentábamos. Aunque es obvio no queremos dejar de decir que ya estamos pensando en el II Congreso. Seguramente será mucho mejor que el de Algeciras por las lecciones aprendidas y, sobre todo, las sugerencias que estamos recibiendo de muchos de los participantes. Tenemos que innovar en las comunicaciones en formato póster, tanto en el presencial como en el virtual. Es el medio que más ha tendido a usar el docente no universitario, menos acostumbrado a los congresos científicos, y tenemos que lograr que sea un espacio que propicie más encuentros y colaboraciones.

Otra de las acciones que deseamos estamos a punto de lanzar es la Revista lberoamérica de Docentes que pueda ser cauce de exposición pública de las experiencias docentes, así como de trabajos de investigación [ojalá muy colaborativos] sobre aspectos esenciales de la educación. Muchos docentes iberoamericanos están realizando innovaciones en su día a día educativo y son poco conocidas. Esa es una lección que hemos aprendido y queremos que una revista que junto a recibir originales sea capaz de ayudarles a que esa comunicación se ajuste a los parámetros esperables de una comunicación científica es un gran aporte para la educación iberoamericana.

Y el reto fundamental, al mismo tiempo que fundacional, es el de propiciar la colaboración entre docentes. El propio Congreso ha sido el punto de partida de muchas colaboraciones entre personas que se han conocido en Algeciras, o en el espacio virtual, y que por intereses afines ya han empezado a colaborar.

En el mismo espacio de la Revista, al que hemos incorporado a los congresistas, vamos a ir programando videoconferencias mensuales que ofrezcan un marco teórico a configurar equipos [de 5/6 miembros] para colaborar en avanzar en el conocimiento.

En 2016 Jordi Adell en una entrevista en Plataforma Reivindicativa decía:

En España hay 800.000 docentes. Pongamos que cada uno de ellos publica una actividad didáctica que le haya funcionado. Quizá 750.000 no son lo suficientemente buenas o son repetitivas. Aún tenemos 50.000 que, si las organizamos en la nube, nos proporciona enormes posibilidades. Al final la virtud de la red es que está conformada por personas. Internet no es un cuarto de herramientas, sino un ágora llena de gente.

Si su frase la extendemos a toda Iberoamérica seguramente estemos hablando de 8.000.000 de docentes.

Nos queda mucho trabajo, pero estamos acompañados con especialistas del mayor nivel que creen, al igual que nosotros, en la potencia de la colaboración entre docentes. 


\section{REFERENCIAS}

Blázquez, C. [2016]. Jordi Adell. Que un niño saque un cuatro no significa que sepa la mitad de uno que saca un ocho. Educative.com.

https:// www.la educacioncuantica.org/educacioncuantica/ SEducacionCuantica?PN=16\&PE=2\&WEBLANG=1\&NOTICIA=1096 Recuperado, 16 de marzo, 2019.

\section{ENLACES RELACIONADOS:}

Red Iberoamericana de Docentes: http://redesib.formacionib.org

I Congreso lberoamericano de Docentes [espacio difusión] http:/ / congreso.formacionib.org Formación lb: http:/ / formacionib.org

Espacio colaborativo de la Revista Iberoamericana de Docentes: https:/ / revistaib.com/ 